\title{
Dynamics of the Green and Red Upconversion Emissions in $\mathrm{Yb}^{3+}-\mathrm{Er}^{3+}$-Codoped $\mathrm{Y}_{2} \mathrm{O}_{3}$ Nanorods
}

\author{
O. Meza, ${ }^{1}$ L. A. Diaz-Torres, ${ }^{1}$ P. Salas, ${ }^{2}$ C. Angeles-Chavez, ${ }^{3}$ A. Martínez, ${ }^{4}$ \\ J. Morales, ${ }^{4}$ and J. Oliva ${ }^{1}$ \\ ${ }^{1}$ Grupo de Espectroscopia de Materiales Avanzados y Nanoestructurados (EMANA), Centro de Investigaciones en Óptica, A. C., \\ A. P. 1-948, 37160 León, Mexico \\ ${ }^{2}$ Centro de Física Aplicada y Tecnología Avanzada, Universidad Nacional Autónoma de México, \\ A. P. 1-1010, 76000 Querétaro, QRO, Mexico \\ ${ }^{3}$ Programa de Ingeniería Molecular, Instituto Mexicano del Petróleo, A. P. 14-805, 07730 Mexico, D.F., Mexico \\ ${ }^{4}$ Universidad Autónoma Metropolitana-Azcapotzalco, DCBI-Ciencias Básicas, Área de Física Atómica Molecular Aplicada, \\ Sn Pablo 180, 02200 Mexico, D.F., Mexico
}

Correspondence should be addressed to L. A. Diaz-Torres, ditlacio@cio.mx

Received 28 January 2010; Accepted 4 June 2010

Academic Editor: Kui Yu

Copyright (๑) 2010 O. Meza et al. This is an open access article distributed under the Creative Commons Attribution License, which permits unrestricted use, distribution, and reproduction in any medium, provided the original work is properly cited.

\begin{abstract}
Efficient green and red upconversion emission in $\mathrm{Y}_{2} \mathrm{O}_{3}: \mathrm{Yb}^{3+}, \mathrm{Er}^{3+}$ nanorods under $978 \mathrm{~nm}$ radiation excitation is achieved. Experimental effective lifetimes, luminescent emissions, and nanorod sizes depend strongly on the solvent ratios used during the synthesis. A microscopic nonradiative energy transfer model is used to approach the dynamics of the green, red, and infrared emissions. The excellent agreement between simulated and experimental decay suggests that the energy transfer mechanisms responsible of the visible emission depend on the solvent ratio.
\end{abstract}

\section{Introduction}

Synthesis and optical characterization of luminescent materials in their nanocrystalline form have led to their growing use in numerous military and medical applications, such as imaging, range finding, flash lidar, and remote sensing [14]. Yttrium Oxide $\left(\mathrm{Y}_{2} \mathrm{O}_{3}\right)$ has been the material of choice for photonics applications, owing to its favorable physical properties and ease of synthesis in the nanometer regime [57]. In particular, nanometer-sized rare earth-doped $\mathrm{Y}_{2} \mathrm{O}_{3}$ has shown enhanced luminescence and quantum yields relative to its bulk counterparts [8]. Very recently, a great deal of research has focused on finding lanthanide-doped inorganic nanocrystalline materials that will undergo near infrared (NIR) to-visible upconversion $[6,9]$. The $\mathrm{Er}^{3+}$ ion has a relatively low absorption cross-section for the transitions in the near-infrared (NIR) region around $1000 \mathrm{~nm}$. On the other hand, the $\mathrm{Yb}^{3+}$ ion exhibits a larger absorption cross-section in this region, and thus, codoping with $\mathrm{Yb}^{3+}$ has proven to be a successful alternative for enhanced upconversion processes. In fact, there is a large spectral overlap between the ${ }^{2} \mathrm{~F}_{5 / 2} \rightarrow{ }^{2} \mathrm{~F}_{7 / 2} \mathrm{Yb}^{3+}$ NIR emission and the ${ }^{4} \mathrm{I}_{11 / 2} \rightarrow{ }^{4} \mathrm{I}_{15 / 2} \mathrm{Er}^{3+}$ absorption bands, which results in an efficient nonradiative energy transfer process, and in turn efficient upconversion emission. Some of the most important parameters on luminescent materials are the lifetime and quantum yield. Both parameters are related to nonradiative energy transfer processes among active ions within the host. There are several models that attempt to explain the lifetime and quantum yield dependence on nonradiative energy transfer rates. The pioneering works of Forster [10], continued later by Dexter [11] and Inokuti and Hirayama [12] allowed the estimation of the non radiative energy-transfer rates based on experimental fluorescence lifetime measurements [13]. With varying degrees of acceptance, all these models have been applied to a large variety of crystalline systems in spite of the fact that hose models consider that the luminescent centers are continuously distributed within the luminescent host. This certainly is not the case in a crystalline medium, where the ions are distributed in very specific positions 
within the crystal lattice. Further, the discreteness of the active ions distribution within the crystalline lattice might become increasingly important as we consider nanometersized luminescent materials. So, there is a need to revise those models and formulate alternative ones.

In this paper, we consider the discrete distribution of the active ions $\left(\mathrm{Er}^{3+}\right.$ and $\mathrm{Yb}^{3+}$ ions) within the crystalline lattice to study the nonradiative energy transfer processes that lead to the visible upconverted emission in $\mathrm{Y}_{2} \mathrm{O}_{3} \mathrm{Er}^{3+}$ $\mathrm{Yb}^{3+}$-codoped nanorods. $\mathrm{Y}_{2} \mathrm{O}_{3}$ nanorod samples were synthesized by hydrothermal method using two ethanol/water solvent ratios (SRs), 1:10 and 1:5. Experimental effective lifetimes, luminescent emissions, and nanorod sizes depend strongly on the SRs. A nonradiative energy transfer model is proposed to numerical simulate the dynamics of the excitation energy among the active ions as well as their emission fluorescence decays. By doing that we extend the understanding of the non radiative energy transfer process that affect the photoluminescent properties of $\mathrm{Er}^{3+}$ and $\mathrm{Yb}^{3+}$ ions in $\mathrm{Y}_{2} \mathrm{O}_{3}$ nanorods. These simulations results indicate that solvent concentration plays an important role on the upconversion luminescence processes, and therefore a change in the lifetime and quantum yield will be observed. It bears mentioning that our model is the only one at present that considers the discreet nature of the nanocrystals; in addition it also can consider more than one exited state (energy level) of the ions. All the above advantages are in contrast to the traditional models by Vasquez [13], Jerez et al. [14] and Parisi et al. [15], which do not consider the discreteness of the nanocrystals and are suitable only for systems of two levels ions.

\section{Experimental}

The $\mathrm{Y}_{2} \mathrm{O}_{3}: \mathrm{Yb}^{3+}, \mathrm{Er}^{3+}$ nanorods, codoped with $1 \mathrm{~mol} \%$ of $\mathrm{Er}_{2} \mathrm{O}_{3}$ and $2 \mathrm{~mol} \%$ of $\mathrm{Yb}_{2} \mathrm{O}_{3}$, were synthesized by the hydrothermal precipitation method via cetyltrimethyl ammonium bromide (CTAB) complexation, for two different ethanol to water SRs, $1: 5$ and $1: 10$. All chemicals were reagent grade supplied by Aldrich, Inc. Samples were obtained using as precursors $\mathrm{YCl}_{3} 6 \mathrm{H}_{2} \mathrm{O}, \operatorname{Er}\left(\mathrm{NO}_{3}\right)_{3} 5 \mathrm{H}_{2} \mathrm{O}$, $\mathrm{YbCl}_{3} 6 \mathrm{H}_{2} \mathrm{O}$, and CTAB as cationic surfactant. In both cases, all components were mixed in the corresponding ethanol to water SR, at room temperature, under vigorous stirring. The precipitation was achieved by adding sodium hydroxide and the resulting solution was transferred into a sealed autoclave maintained at $100^{\circ} \mathrm{C}$ during $20 \mathrm{~h}$. The precipitate was then washed with distilled water and dried in an oven at $100^{\circ} \mathrm{C}$ for $15 \mathrm{~h}$. Then it was annealed at $1000^{\circ} \mathrm{C}$ for $3 \mathrm{~h}$, with a heating rate of $31^{\circ} \mathrm{C} / \mathrm{min}$. X-ray diffraction (XRD) patterns were obtained using SIEMENS D-5005 equipment provided with a $\mathrm{Cu}$ tube with $K_{\alpha}$ radiation at $1.5405 \AA$, scanning in the $15-80^{\circ} 2 \theta$ range with increments of $0.02^{\circ}$ and a swept time of $2 \mathrm{~s}$. Transmission electron microscopy (TEM) was performed in JEM-2200FS transmission electron microscope with accelerating voltage of $200 \mathrm{kV}$. The photoluminescence characterization was performed under $978 \mathrm{~nm}$ excitation forming a tunable OPO system (MOPO from Spectra Physics) pumped by the third harmonic of a
10 ns Nd:YAG pulsed laser. The fluorescence emission was analyzed with an Acton Pro 500i monochromator and two Hamamatsu photomultiplier tubes (R7400U-20 for VIS and for R3809U-68 for NIR) connected to an SR860 lock-in amplifier (Stanford Research). Fluorescence lifetimes were measured by connecting the photomultiplier to a $500 \mathrm{MHz}$ Lecroy digital Oscilloscope. The system was controlled with a PC were emission spectra and decay trends where registered. All photoluminescence measurements were done at room temperature.

\section{Model and Theory}

The microscopic origin for nonradiative energy transfer processes can be visualized as an interaction between an excited ion, the donor D, and another not excited ion, the acceptor A, with an absorption transition resonant with the deexcitation of the first one $[10,11,16]$. In the case of $\mathrm{Y}_{2} \mathrm{O}_{3}: \mathrm{Yb}^{3+}, \mathrm{Er}^{3+}$ under pumping at $978 \mathrm{~nm}, \mathrm{Yb}^{3+}$ ions can be visualized as donors and $\mathrm{Er}^{3+}$ ions as acceptors due to absorption cross-section differences between the $\mathrm{Yb}\left({ }^{2} \mathrm{~F}_{5 / 2}\right)$ and $\operatorname{Er}\left({ }^{4} \mathrm{I}_{11 / 2}\right)$ energy levels [17]. The corresponding nonradiative energy transfer rate between $i$ th $\mathrm{Yb}^{3+}$ ion and the $j$ th $\mathrm{Er}^{3+}$ ion is given by [18]

$$
W\left(\mathrm{Yb}_{\mathrm{FS}}^{\mathrm{IS}} \longrightarrow \mathrm{Er}_{\mathrm{ES}}^{\mathrm{IS}}\right)_{i j}=\frac{C\left(\mathrm{Yb}_{\mathrm{FS}}^{\mathrm{IS}} \longrightarrow \mathrm{Er}_{\mathrm{ES}}^{\mathrm{IS}}\right)}{\left(R\left(\mathrm{Yb}_{i}, \mathrm{Er}_{j}\right)\right)^{6}}
$$

where $R\left(\mathrm{Yb}_{i}, \mathrm{Er}_{j}\right)$ is the distance between the $i$ th $\mathrm{Yb}$ ion and the $j$ th $\mathrm{Er}$ ion, $C\left(\mathrm{Yb}_{\mathrm{FS}}^{\mathrm{IS}} \longrightarrow \operatorname{Er}_{\mathrm{ES}}^{\mathrm{IS}}\right)$ is the dipole-dipole microinteraction strength parameter $[11,19]$. For simplicity we represent this process by $W\left(\mathrm{Yb}_{\mathrm{FS}}^{\mathrm{IS}} \longrightarrow \mathrm{Er}_{\mathrm{ES}}^{\mathrm{IS}}\right)_{i j}$. This notation indicates that the $i$ th $\mathrm{Yb}^{3+}$ ion has a nonradiative relaxation from an initial state IS to a final state FS, and the freed energy excites the $j$ th $\mathrm{Er}^{3+}$ ion from an initial state IS up to an excited state ES.

Under $978 \mathrm{~nm}$ pulsed excitation, the $\mathrm{Er}^{3+}$ ions are excited from the ground state ${ }^{4} \mathrm{I}_{15 / 2}$ to the excited state ${ }^{4} \mathrm{I}_{11 / 2}$, mainly by the phonon-assisted nonradiative energy transfer $(\mathrm{ET})$ process $\mathrm{Yb}^{3+}\left({ }^{2} \mathrm{~F}_{5 / 2},{ }^{2} \mathrm{~F}_{7 / 2}\right) \rightarrow \mathrm{Er}^{3+}\left({ }^{4} \mathrm{I}_{15 / 2},{ }^{4} \mathrm{I}_{11 / 2}\right)$. Then, the populated ${ }^{4} \mathrm{I}_{11 / 2}$ level is excited to the ${ }^{4} \mathrm{~F}_{7 / 2}$ level mainly by phonon-assisted ET from excited $\mathrm{Yb}^{3+}$ ions [7]. The populated ${ }^{4} \mathrm{~F}_{7 / 2}$ state rapidly relaxes to the two lower levels: ${ }^{2} \mathrm{H}_{11 / 2}$ and ${ }^{4} \mathrm{~S}_{3 / 2}$, which produce green upconversion luminescence. So, in our model we consider this process as an overall $\mathrm{Yb}^{3+}\left({ }^{2} \mathrm{~F}_{5 / 2},{ }^{2} \mathrm{~F}_{7 / 2}\right) \rightarrow \mathrm{Er}^{3+}\left({ }^{4} \mathrm{I}_{11 / 2},{ }^{2} \mathrm{H}_{11 / 2}+{ }^{4} \mathrm{~S}_{3 / 2}\right)$ non radiative ET process instead of the $\mathrm{Yb}^{3+}\left({ }^{2} \mathrm{~F}_{5 / 2},{ }^{2} \mathrm{~F}_{7 / 2}\right) \rightarrow$ $\mathrm{Er}^{3+}\left({ }^{4} \mathrm{I}_{11 / 2},{ }^{4} \mathrm{~F}_{7 / 2}\right)$ ET followed by the nonradiative relaxation $\operatorname{Er}^{3+}\left({ }^{4} \mathrm{~F}_{7 / 2}\right) \rightarrow \operatorname{Er}^{3+}\left({ }^{4} \mathrm{I}_{11 / 2},{ }^{2} \mathrm{H}_{11 / 2}+{ }^{4} \mathrm{~S}_{3 / 2}\right)$. In addition, the populated $\mathrm{Er}^{3+}\left({ }^{4} \mathrm{I}_{11 / 2}\right)$ state mostly relaxes to the long-living $\mathrm{Er}^{3+}\left({ }^{4} \mathrm{I}_{13 / 2}\right)$ state. Electrons in the $\mathrm{Er}^{3+}\left({ }^{4} \mathrm{I}_{13 / 2}\right)$ state may be promoted to the upper $\mathrm{Er}^{3+}\left({ }^{4} \mathrm{~F}_{9 / 2}\right)$ state by the ET process $\mathrm{Yb}^{3+}\left({ }^{2} \mathrm{~F}_{5 / 2},{ }^{2} \mathrm{~F}_{7 / 2}\right) \rightarrow \mathrm{Er}^{3+}\left({ }^{4} \mathrm{I}_{13 / 2},{ }^{4} \mathrm{~F}_{9 / 2}\right)$. The populated ${ }^{4} \mathrm{~F}_{9 / 2}$ level mostly relaxes radiatively to the ground state ${ }^{4} \mathrm{I}_{15 / 2}$ level, which causes the Er red emissions. For simplicity in our model the $\mathrm{Yb}^{3+}\left({ }^{2} \mathrm{~F}_{5 / 2},{ }^{2} \mathrm{~F}_{7 / 2}\right) \rightarrow \operatorname{Er}^{3+}\left({ }^{4} \mathrm{I}_{15 / 2},{ }^{4} \mathrm{I}_{11 / 2}\right)$, $\mathrm{Yb}^{3+}\left({ }^{2} \mathrm{~F}_{5 / 2},{ }^{2} \mathrm{~F}_{7 / 2}\right) \rightarrow \mathrm{Er}^{3+}\left({ }^{4} \mathrm{I}_{13 / 2},{ }^{4} \mathrm{~F}_{9 / 2}\right)$, and $\mathrm{Yb}^{3+}\left({ }^{2} \mathrm{~F}_{5 / 2},{ }^{2} \mathrm{~F}_{7 / 2}\right)$ $\rightarrow \operatorname{Er}^{3+}\left({ }^{4} \mathrm{I}_{11 / 2},{ }^{2} \mathrm{H}_{11 / 2}+{ }^{4} \mathrm{~S}_{3 / 2}\right)$ transition were denoted by 
$W\left(\mathrm{Yb}_{0}^{1} \rightarrow \mathrm{Er}_{2}^{0}\right), W\left(\mathrm{Yb}_{0}^{1} \rightarrow \mathrm{Er}_{3}^{1}\right)$, and $W\left(\mathrm{Yb}_{0}^{1} \rightarrow \mathrm{Er}_{4}^{2}\right)$, respectively; see Figure 1.

By taking into account the above described ET processes one can write down ordinary differential equations that govern the excitation dynamics among all $\mathrm{Yb}^{3+}$ and $\mathrm{Er}^{3+}$ ions inside of an arbitrary $\mathrm{Y}_{2} \mathrm{O}_{3}: \mathrm{Yb}^{3+}, \mathrm{Er}^{3+}$ nanocrystal:

$$
\begin{aligned}
& \frac{d P_{\mathrm{Yb}_{i}}^{1}}{d t}=-\frac{1}{\tau\left(\mathrm{Yb}_{0}^{1}\right)} P_{\mathrm{Yb}_{i}}^{1}-\sum_{m=1}^{N_{\mathrm{Er}}} W\left(\mathrm{Yb}_{0}^{1} \longrightarrow \mathrm{Er}_{2}^{0}\right)_{i m} P_{\mathrm{Yb}_{i}}^{1} P_{\mathrm{Er}_{m}}^{0} \\
& -\sum_{m=1}^{N_{\mathrm{Er}}} W\left(\mathrm{Yb}_{0}^{1} \longrightarrow \mathrm{Er}_{3}^{1}\right)_{i m} P_{\mathrm{Yb}_{i}}^{1} P_{\mathrm{Er}_{m}}^{1} \\
& -\sum_{m=1}^{N_{\mathrm{Er}}} W\left(\mathrm{Yb}_{0}^{1} \longrightarrow \mathrm{Er}_{4}^{2}\right)_{i m} P_{\mathrm{Yb}_{i}}^{1} P_{\mathrm{Er}_{m}}^{2} \\
& \frac{d P_{\mathrm{Er}_{j}}^{1}}{d t}=-\frac{1}{\tau\left(\mathrm{Er}_{0}^{1}\right)} P_{\mathrm{Er}_{j}}^{1}+\frac{1}{\tau\left(\mathrm{Er}_{1}^{2}\right)} P_{\mathrm{Er}_{j}}^{2} \\
& -\sum_{m=1}^{N_{\mathrm{Yb}}} \mathrm{W}\left(\mathrm{Yb}_{0}^{1} \longrightarrow \mathrm{Er}_{3}^{1}\right)_{m j} P_{\mathrm{Yb}_{m}}^{1} P_{\mathrm{Er}_{j}}^{1} \\
& \frac{d P_{\mathrm{Er}_{j}}^{2}}{d t}=-\frac{1}{\tau\left(\mathrm{Er}_{0}^{2}\right)} P_{\mathrm{Er}_{j}}^{2}-\frac{1}{\tau\left(\mathrm{Er}_{1}^{2}\right)} P_{\mathrm{Er}_{j}}^{2}+\frac{1}{\tau\left(\mathrm{Er}_{2}^{3}\right)} P_{\mathrm{Er}_{j}}^{3} \\
& +\sum_{m=1}^{N_{\mathrm{Yb}}} W\left(\mathrm{Yb}_{0}^{1} \longrightarrow \mathrm{Er}_{2}^{0}\right)_{m j} P_{\mathrm{Yb}_{m}}^{1} P_{\mathrm{Er}_{j}}^{0} \\
& -\sum_{m=1}^{N_{\mathrm{Yb}}} W\left(\mathrm{Yb}_{0}^{1} \longrightarrow \mathrm{Er}_{4}^{2}\right)_{m j} P_{\mathrm{Yb}_{m}}^{1} \mathrm{P}_{\mathrm{Er}_{j}}^{2} \\
& \frac{d P_{\mathrm{Er}_{j}}^{3}}{d t}=-\frac{1}{\tau\left(\mathrm{Er}_{0}^{3}\right)} P_{\mathrm{Er}_{j}}^{3}-\frac{1}{\tau\left(\mathrm{Er}_{2}^{3}\right)} P_{\mathrm{Er}_{j}}^{3}+\frac{1}{\tau\left(\mathrm{Er}_{3}^{4}\right)} P_{\mathrm{Er}_{j}}^{4} \\
& +\sum_{m=1}^{N_{\mathrm{Yb}}} W\left(\mathrm{Yb}_{0}^{1} \longrightarrow \mathrm{Er}_{3}^{1}\right)_{m j} P_{\mathrm{Yb}_{m}}^{1} P_{\mathrm{Er}_{j}}^{1}, \\
& \frac{d P_{\mathrm{Er}_{j}}^{4}}{d t}=-\frac{1}{\tau\left(\mathrm{Er}_{0}^{4}\right)} P_{\mathrm{Er}_{j}}^{4}-\frac{1}{\tau\left(\mathrm{Er}_{3}^{4}\right)} P_{\mathrm{Er}_{j}}^{4} \\
& +\sum_{m=1}^{N_{\mathrm{Yb}}} W\left(\mathrm{Yb}_{0}^{1} \longrightarrow \mathrm{Er}_{4}^{2}\right)_{m j} P_{\mathrm{Yb}_{m}}^{1} P_{\mathrm{Er}_{j}}^{2}
\end{aligned}
$$

where $P_{\mathrm{Yb}_{i}}^{1}$ is the probability to finding the $i$ th $\mathrm{Yb}^{3+}$ ion at its exited state ${ }^{2} \mathrm{~F}_{5 / 2}$ at the time $t . P_{\mathrm{Er}_{i}}^{X}$ is probability to finding the $j$ th $\mathrm{Er}^{3+}$ ion at its $X$ state (with $X=1,2,3,4$, corresponding to the states ${ }^{4} \mathrm{I}_{13 / 2},{ }^{4} \mathrm{I}_{15 / 2},{ }^{4} \mathrm{I}_{11 / 2},{ }^{4} \mathrm{~F}_{9 / 2}$ and $\left({ }^{2} \mathrm{H}_{11 / 2}+{ }^{4} \mathrm{~S}_{3 / 2}\right)$, resp.) at the time $t . \tau\left(\mathrm{Yb}_{0}^{1}\right)$ and $\tau\left(\mathrm{Er}_{0}^{\mathrm{IS}}\right)$ are the free ion lifetimes for $\mathrm{Yb}^{3+}$ and $\mathrm{Er}^{3+}$, respectively, from the level IS to ground state, when no energy processes are present (see Table 1). And $1 / \tau\left(\mathrm{Er}_{\mathrm{ES}}^{\mathrm{IS}}\right)$ are the relaxation rates of the $\mathrm{Er}^{3+}$ ions from its upper state IS to the next lower state FS $=$ IS -1 , for IS $=4,3,2$ (see Table 1 ). $N_{\mathrm{Yb}}$ and $N_{\mathrm{Er}}$ are the total number of active ions inside of the $\mathrm{Y}_{2} \mathrm{O}_{3}: \mathrm{Yb}^{3+}, \mathrm{Er}^{3+}$ nanocrystal.
$\mathrm{Y}_{2} \mathrm{O}_{3}$ is a cubic perovskite with spatial group symmetry Ia3 (206) $[21,22]$. Using the coordinate data from Crystallographic tables for the spatial group Ia3(206) [23] a $k$ th nanocrystal sample is numerically generated. Then the $\mathrm{Yb}^{3+}$ and $\mathrm{Er}^{3+}$ dopant ions are placed into the potential $24 \mathrm{~d}$ and $8 \mathrm{~b}$ crystal sites with a random uniform distribution by using the Monte Carlo method. With this random uniform placement $\mathrm{Er}^{3+}$ and $\mathrm{Yb}^{3+}$ ions each have a particular distribution of neighboring $\mathrm{Er}^{3+}$ and $\mathrm{Yb}^{3+}$ codopants within the particular $k$ th generated nanocrystal. Thus, based on actual interionic distances and by assuming a dipole-dipole microinteraction strength parameter we compute all the non radiative transfer rates among ion pairs for the considered transfer processes (see Figure 1). After that, we are in the position to solve (2) by a fourth-order Runge-Kutta Method [24]. Notice that the only free parameters are the $C\left(\mathrm{Yb}_{\mathrm{FS}}^{\mathrm{IS}} \rightarrow \mathrm{ER}_{\mathrm{ES}}^{\mathrm{IS}}\right)$ parameters. $i$ th $\mathrm{Yb}^{3+}$ and $j$ th $\mathrm{Er}^{3+}$ ions each have its own decay rate proportional to its own $P_{\mathrm{Yb}_{i}}^{1} P_{\mathrm{Yb}_{i}}^{1}$ and $P_{\mathrm{Er}_{j}}^{X} P_{\mathrm{Er}_{i}}^{X}$ probability of being exited at time $t$. Thus, the total fluorescence emission transient from the $k$ th generated crystal will be the average over the individual emissions overall active ions within the $k$ th nanocrystal, and the macroscopic emission will be proportional to the average over a large number of $k$ numerically generated crystal samples, that is,

$$
\begin{aligned}
\varphi_{\mathrm{Yb}}(t) & =\left\langle\left\langle P_{\mathrm{Yb}_{\mathrm{i}}}^{1}\right\rangle_{\text {av.overi }}\right\rangle_{\text {av.overk }}, \\
\varphi_{\mathrm{Er}}^{\mathrm{X}}(t) & =\left\langle\left\langle P_{\mathrm{Er}_{\mathrm{j}}}^{1}\right\rangle_{\text {av.over } j}\right\rangle_{\text {av.overk }} .
\end{aligned}
$$

\section{Results and Discussion}

The XRD patterns of the $\mathrm{Y}_{2} \mathrm{O}_{3}: \mathrm{Yb}^{3+}, \mathrm{Er}^{3+}$ nanocrystalline powders prepared with $1: 5$ and $1: 10$ ethanol/water ratios (SR) are shown in Figure 2. Both samples exhibit almost identical patterns and the main characteristic diffraction peaks can be indexed as a pure cubic phase (space group Ia3 (206)) with cell parameter of $10.6056 \AA 10.5818 \AA$ for the water to ethanol SR $1: 10$ and $1: 5$, respectively. These values are in agreement with the standard value of $10.6 \AA$ for the bulk cubic $\mathrm{Y}_{2} \mathrm{O}_{3}$ reported in card number JCPDS 41-1105 [22]. Figure 2 helps to show the dependency between the solvent radio and interionic distance, which alone affects the nonradiative ET processes for a same dopant concentration. Both samples present single nanorod morphology as can be observed in the TEM micrographics in Figure 3. For the $1: 10$ SR sample the nanorods are $745.6 \mathrm{~nm}$ lengths and $55.2 \mathrm{~nm}$ diameter in average, whereas for $1: 5 \mathrm{SR}$ the nanorods are $1464.8 \mathrm{~nm}$ length and $75.4 \mathrm{~nm}$ diameter. Taking into account the dopant concentration, size, shape, and ions distribution of the nanocrystals, we simulate a great number of nanorods. We estimated the mean $\mathrm{Yb}^{3+}-\mathrm{Er}^{3+}$ distance $\left(\mathrm{R}_{\mathrm{YbEr}}\right)$ for each water to ethanol SR. These $R_{Y b E}$ are $(7.661 \pm 0.020) \AA$ and $(7.820 \pm 0.0482) \AA$, at the $95.0 \%$ confidence level, for $1: 5$ and $1: 10$ SRs, respectively. Thus, form (1) and considering that in both samples the energy transfer processes among $\mathrm{Yb}^{3+}-\mathrm{Er}^{3+}$ pairs are the same, that is, the same dipole-dipole microinteraction strength parameter for each ET process, in general the nonradiative ET processes are expected to be $13 \%$ 


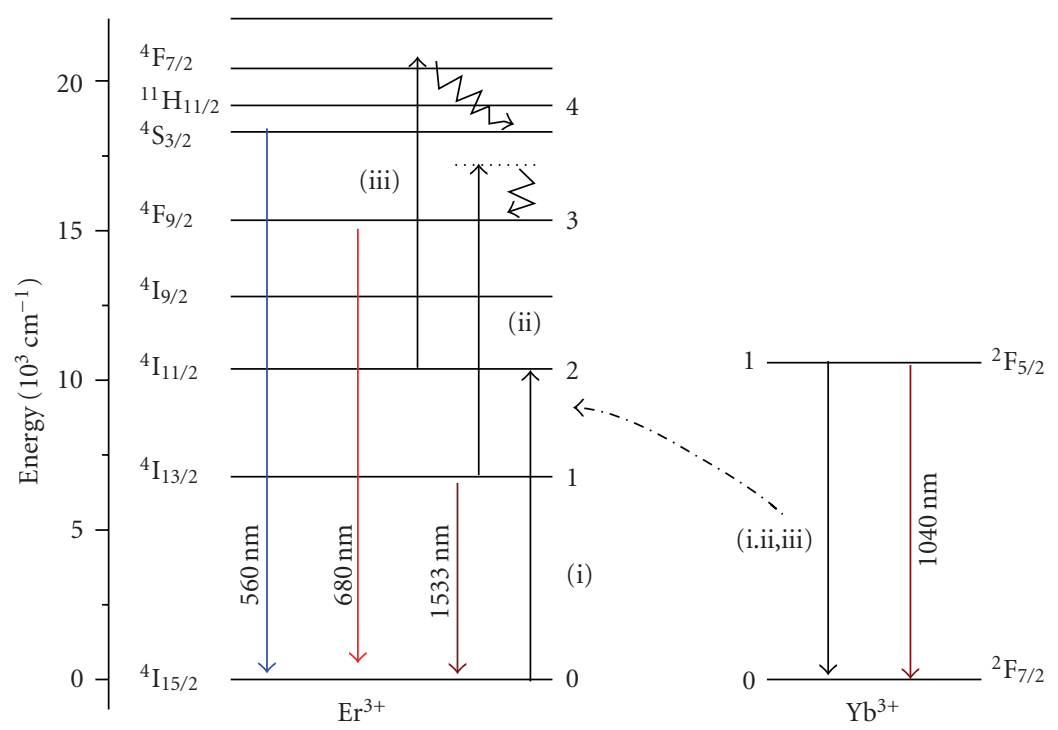

FIGURE 1: Energy levels diagram of $\mathrm{Y}_{2} \mathrm{O}_{3}: \mathrm{Er}^{3+}, \mathrm{Yb}^{3+}$ nanorods and the considered direct $\mathrm{Yb}^{3+}$ to $\mathrm{Er}^{3+}$ nonradiative energy transfer processes: (i) $W\left(\mathrm{Yb}_{0}^{1} \rightarrow \mathrm{Er}_{2}^{0}\right)$, (ii) $W\left(\mathrm{Yb}_{0}^{1} \rightarrow \mathrm{Er}_{3}^{1}\right)$, and (iii) $W\left(\mathrm{Yb}_{0}^{1} \rightarrow \mathrm{Er}_{4}^{2}\right)$.

TABLE 1: Free ion lifetimes of $\mathrm{Yb}^{3+}$ and $\mathrm{Er}^{3+}$ are reported in [20].

\begin{tabular}{ccccccccc}
\hline & $\tau\left(\mathrm{Yb}_{0}^{1}\right)$ & $\tau\left(\mathrm{Er}_{0}^{1}\right)$ & $\tau\left(\mathrm{Er}_{0}^{2}\right)$ & $\tau\left(\mathrm{Er}_{0}^{3}\right)$ & $\tau\left(\mathrm{Er}_{0}^{4}\right)$ & $\tau\left(\mathrm{Er}_{1}^{2}\right)$ & $\tau\left(\mathrm{Er}_{2}^{3}\right)$ & $\tau\left(\mathrm{Er}_{3}^{4}\right)$ \\
\hline Time $(\mu \mathrm{s})$ & 670 & 6030 & 6810 & 644 & 698 & 11.061 & 39.15 & 387.60 \\
\hline
\end{tabular}

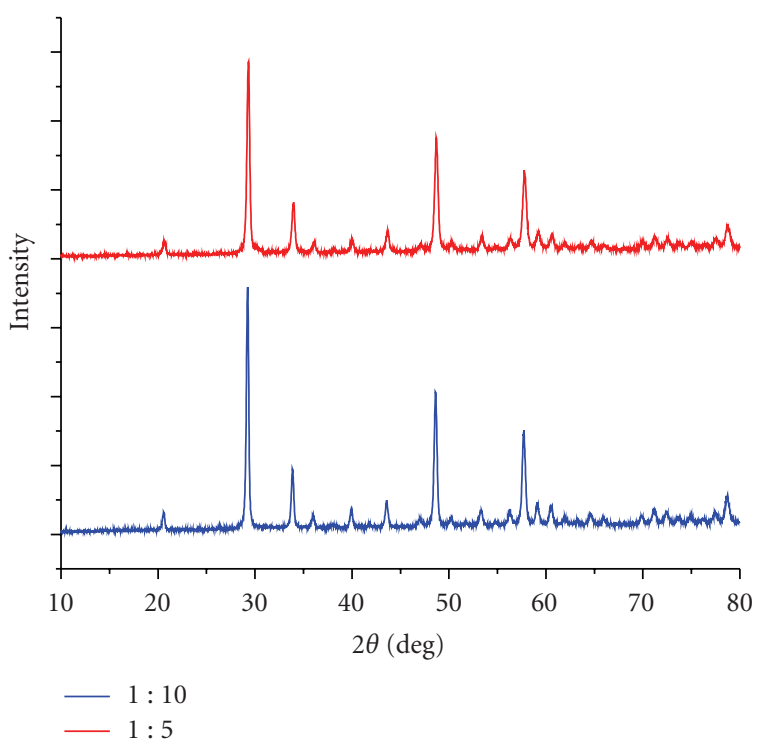

FIGURE 2: XRD patterns of $\mathrm{Y}_{2} \mathrm{O}_{3}: \mathrm{Er}^{3+}, \mathrm{Yb}^{3+}$ nanorods.

stronger in the $1: 5$ solvent ratio sample than for the $1: 10$ SR sample.

The absorption spectra of the $\mathrm{Y}_{2} \mathrm{O}_{3}: \mathrm{Yb}^{3+}, \mathrm{Er}^{3+}$ nanorods for the two studied SRs are shown in Figure 4. The absorption peaks for $\mathrm{Er}^{3+}$ and the corresponding transitions from the ground states are $1536 \mathrm{~nm}\left({ }^{4} \mathrm{I}_{13 / 2}\right), 965 \mathrm{~nm}\left({ }^{4} \mathrm{I}_{11 / 2}\right)$ overlapped with the broad absorption band of $\mathrm{Yb}^{3+}\left({ }^{2} \mathrm{~F}_{5 / 2}\right)$, $800 \mathrm{~nm} \quad\left({ }^{4} \mathrm{I}_{9 / 2}\right), \quad 654 \mathrm{~nm} \quad\left({ }^{4} \mathrm{~F}_{9 / 2}\right), \quad 539 \mathrm{~nm} \quad\left({ }^{4} \mathrm{~S}_{3 / 2}\right), \quad 522 \mathrm{~nm}$ $\left({ }^{2} \mathrm{H}_{11 / 2}\right)$. The new observable feature is a broad peak centered at $1382 \mathrm{~nm}$ indicating the presence of residual $\mathrm{H}_{2} \mathrm{O}$ that could be keeping occluded within the $\mathrm{Y}_{2} \mathrm{O}_{3}$ nanorods. The ratio of the $\mathrm{Er}^{3+}\left({ }^{4} \mathrm{I}_{13 / 2}\right)$ band to the $1385 \mathrm{~nm} \mathrm{H} \mathrm{H}_{2} \mathrm{O}$ band is 3.28 and 1.21 for the $1: 10$ and $1: 5$ SRs, respectively, That is in agreement with the fact that the higher content of occluded $\mathrm{H}_{2} \mathrm{O}$ is found in the sample obtained with a lower SR $(1: 5)$.

Figure 5 shows the VIS spectra of $\mathrm{Y}_{2} \mathrm{O}_{3}$ under $978 \mathrm{~nm}$ excitation for both samples. The green emissions were observed in the range of 510-580 $\mathrm{nm}$, corresponding to the $\left({ }^{2} \mathrm{H}_{11 / 2},{ }^{4} \mathrm{~S}_{3 / 2}\right) \rightarrow{ }^{4} \mathrm{I}_{15 / 2} \mathrm{Er}^{3+}$ transitions, while the red emissions were observed between 640 and $690 \mathrm{~nm}$, corresponding to the ${ }^{4} \mathrm{~F}_{9 / 2} \rightarrow{ }^{4} \mathrm{I}_{15 / 2} \mathrm{Er}^{3+}$ transitions. We can see that the sample with $1: 10$ SR has in general lower emission intensity for all observed visible emissions than the sample with a $1: 5 \mathrm{SR}$, that in principle could be due to quenching of the population of the $\operatorname{Er}^{3+}\left({ }^{4} \mathrm{I}_{13 / 2}\right)$ and $\mathrm{Yb}^{3+}\left({ }^{4} \mathrm{~F}_{5 / 2}\right)$ excited levels by the residual $\mathrm{H}_{2} \mathrm{O}$ responsible of the $1382 \mathrm{~nm}$ band observed in the absorption spectra. Figure 6 shows both experimental and simulated fluorescence decays for the $\mathrm{Yb}^{3+}$ and $\mathrm{Er}^{3+}$ ions for their visible and infrared emissions. The effective lifetime is obtained from the experimental fluorescence decay using the expression [25]:

$$
\tau_{e}=\frac{\int_{0}^{\infty} I(t) d t}{I(t=0)}
$$

where $I(t)$ is the respective fluorescence decay. The quantum yield can be calculated from the ratio of effective lifetime $\left(\tau_{e}\right)$ and free ion lifetime $(\tau)$ [25]. The computed effective life times and quantum efficiencies are reported in 
TABLE 2: Experimental and simulated lifetimes, quantum efficiencies, and microinteraction parameters.

\begin{tabular}{lccccc}
\hline \multirow{2}{*}{ Solvent Ratio [water : ethanol] } & & \multicolumn{2}{c}{$\mathbf{1 : 1 0}$} & \multicolumn{1}{c}{$\mathbf{1 : 5}$} \\
& & Experimental & Simulation & Experimental & Simulation \\
\hline \multirow{2}{*}{ Effective lifetimes $[\mu \mathrm{s}]$} & $\tau_{\mathrm{e}}\left(\mathrm{Er}_{0}^{1}\right)$ & 6046.2 & 6002.9 & 6818.2 & 6779.5 \\
& $\tau_{\mathrm{e}}\left(\mathrm{Er}_{0}^{3}\right)$ & 269.4 & 284.8 & 290.5 & 316.1 \\
& $\tau_{\mathrm{e}}\left(\mathrm{Er}_{0}^{4}\right)$ & 248.4 & 283.0 & 250.3 & 298.4 \\
& $\tau_{\mathrm{e}}\left(\mathrm{Yb}_{0}^{1}\right)$ & 344.9 & 352.1 & 416.9 & 291.3 \\
\hline \multirow{2}{*}{ Visible emission quantum efficiency } & $\mathrm{Q}\left(\mathrm{Er}_{0}^{3}\right)$ & 0.4183 & 0.4422 & 0.4511 & 0.4908 \\
& $\mathrm{Q}\left(\mathrm{Er}_{0}^{4}\right)$ & 0.3559 & 0.4080 & 0.3586 & 0.4275 \\
\hline \multirow{3}{*}{ Dipole-dipoleMicro interactionParameters $\left[\mathrm{cm}^{6} / \mathrm{s}\right]$} & $\mathrm{C}\left(\mathrm{Yb}_{0}^{1} \rightarrow \mathrm{Er}_{2}^{0}\right)$ & $2.4719 \times 10^{-34}$ & $6.4800 \times 10^{-35}$ \\
& $\mathrm{C}\left(\mathrm{Yb}_{0}^{1} \rightarrow \mathrm{Er}_{3}^{1}\right)$ & $1.6340 \times 10^{-34}$ & $1.6340 \times 10^{-34}$ \\
& $\mathrm{C}\left(\mathrm{Yb}_{0}^{1} \rightarrow \mathrm{Er}_{4}^{2}\right)$ & $1.0475 \times 10^{-34}$ & $1.0475 \times 10^{-34}$ \\
\hline
\end{tabular}

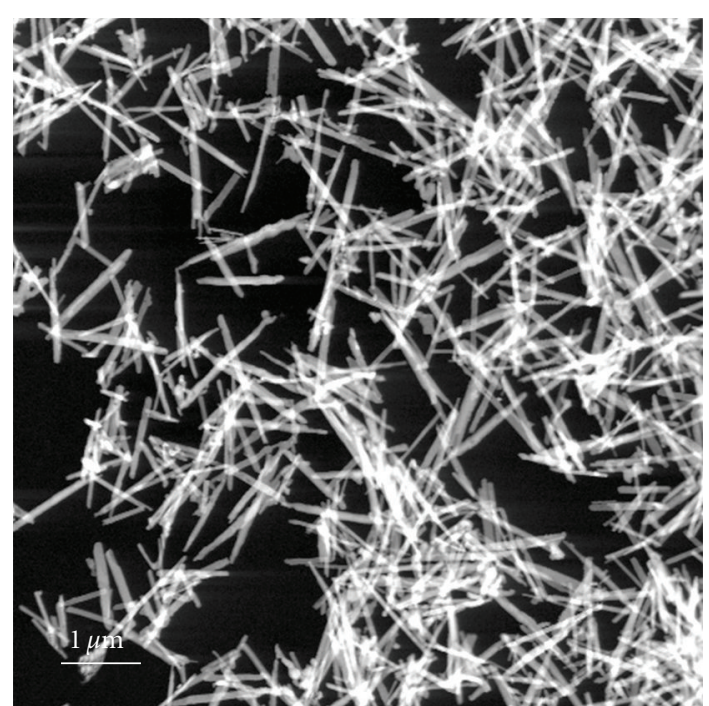

(a)

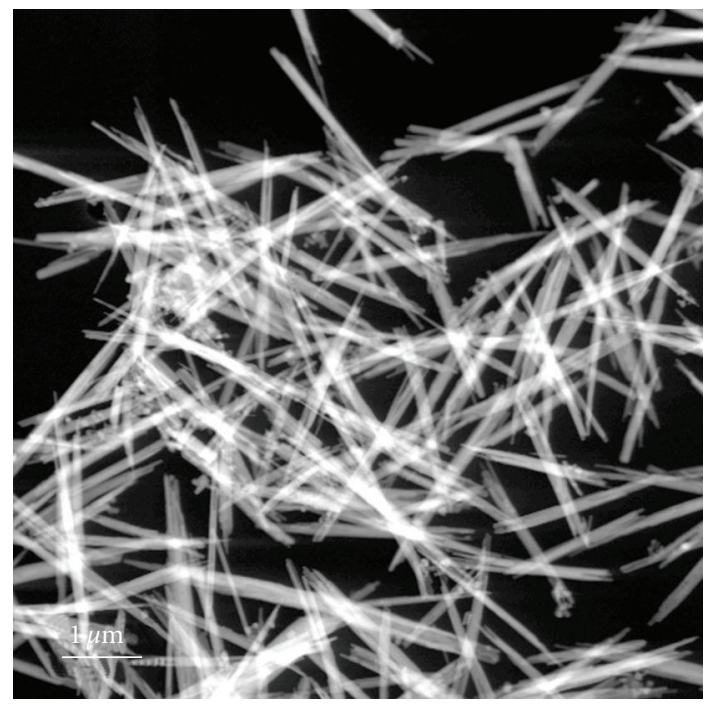

(b)

Figure 3: TEM image of $\mathrm{Y}_{2} \mathrm{O}_{3}: \mathrm{Er}^{3+}, \mathrm{Yb}^{3+}$ nanorods for the water/ethanol solvent radios: (a) $1: 10$ and (b) $1: 5$.

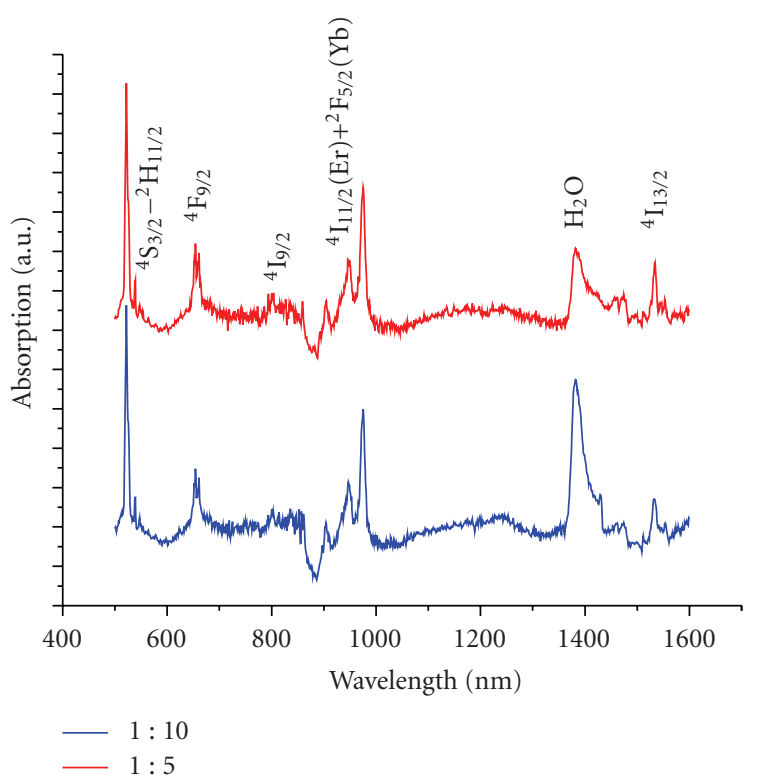

Figure 4: Absorption spectra of $\mathrm{Y}_{2} \mathrm{O}_{3}: \mathrm{Er}^{3+}, \mathrm{Yb}^{3+}$ nanorods.

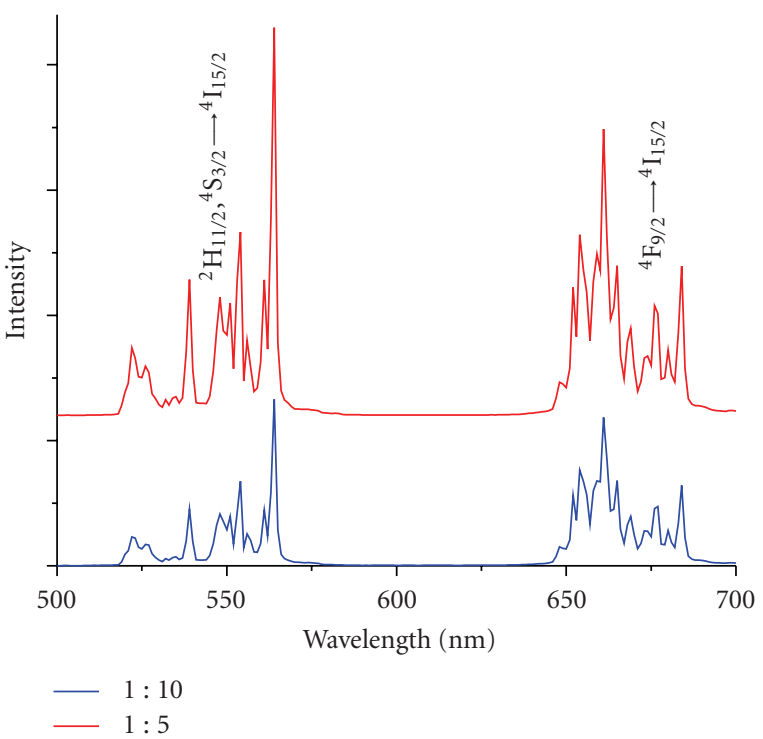

Figure 5: Room temperature visible upconversion spectra of $\mathrm{Y}_{2} \mathrm{O}_{3}: \mathrm{Er}^{3+}, \mathrm{Yb}^{3+}$ nanorods under excitation at $980 \mathrm{~nm}$. 


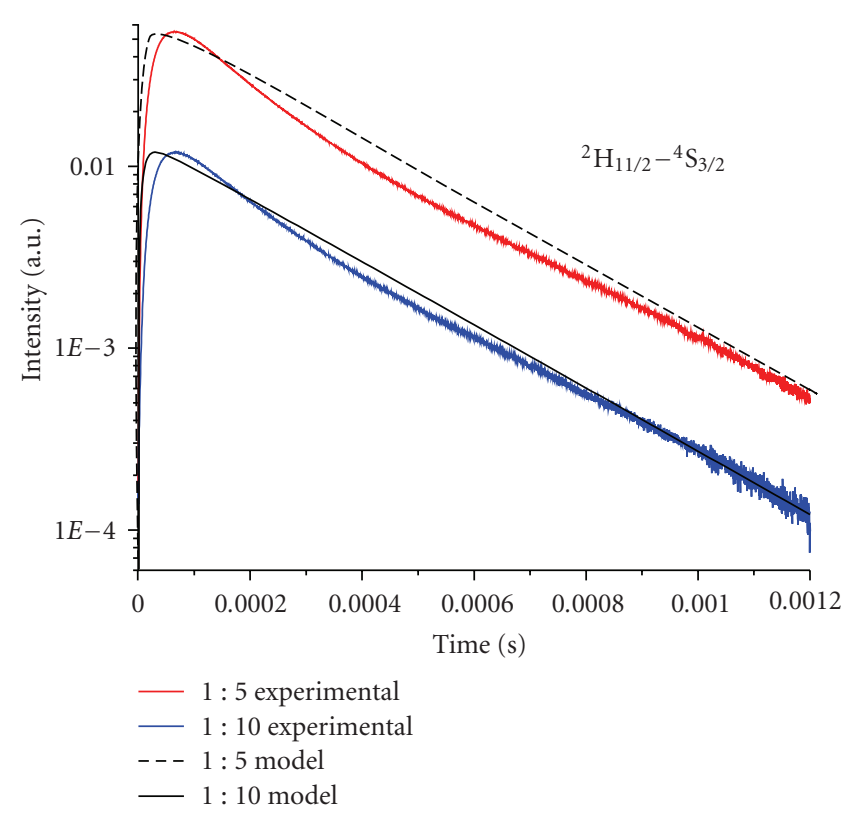

(a)

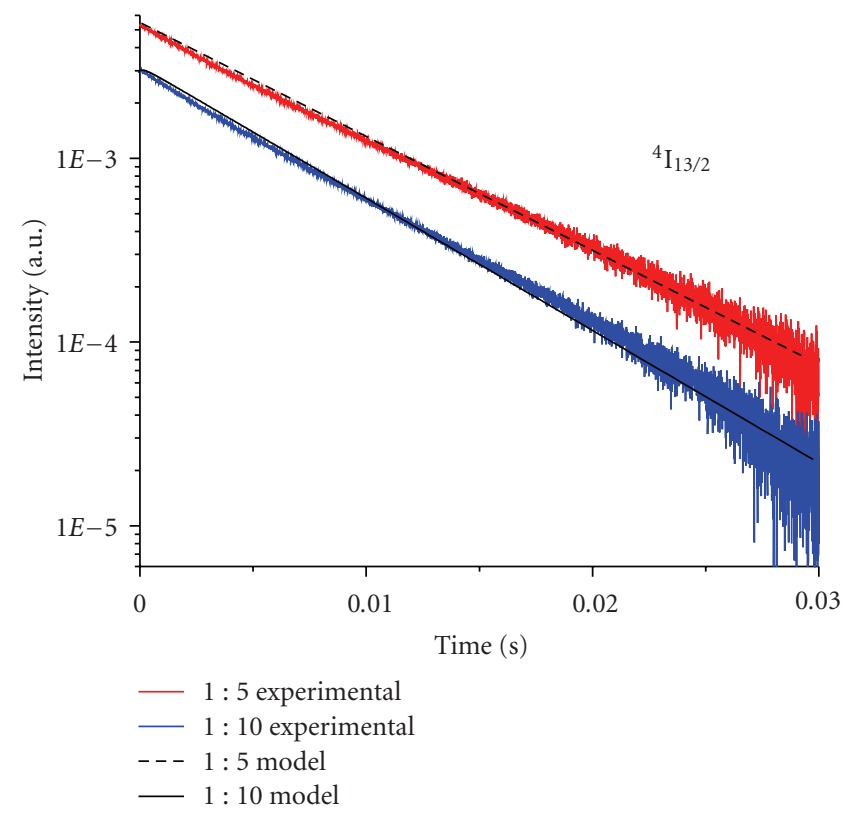

(c)

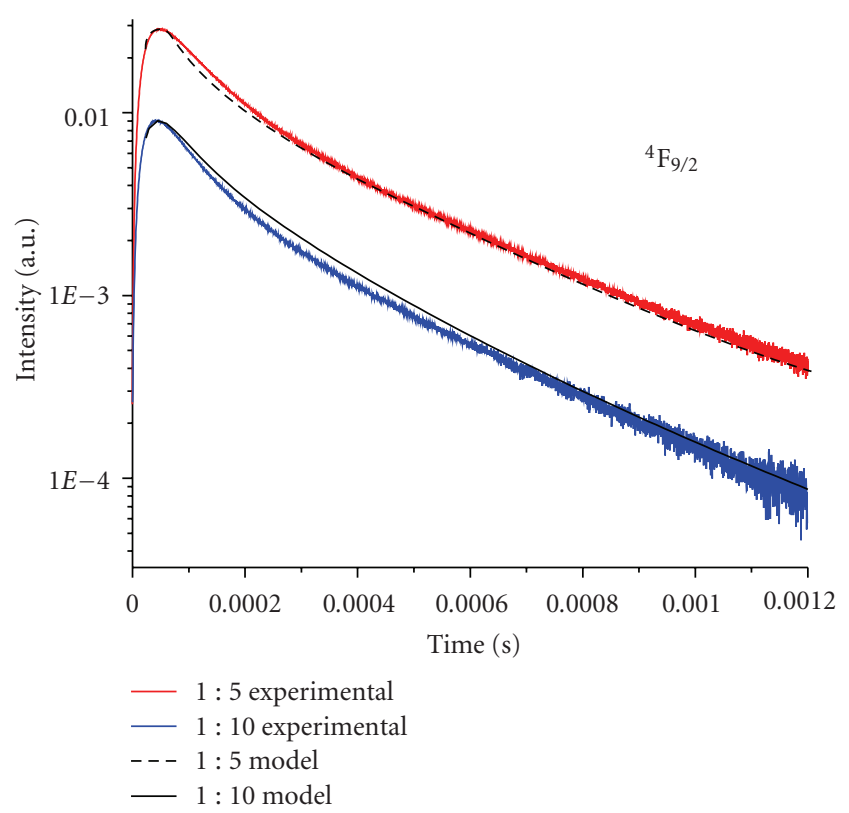

(b)

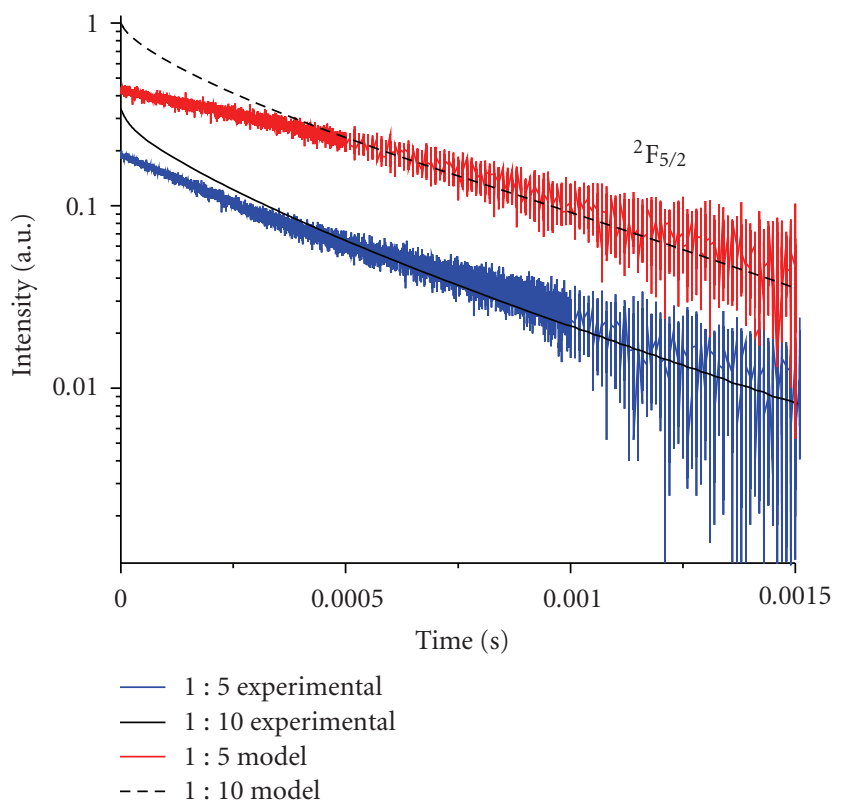

(d)

Figure 6: Experimental and simulated fluorescence decays of the (a) green $\left(\left({ }^{2} \mathrm{H}_{11 / 2},{ }^{4} \mathrm{~S}_{3 / 2}\right) \rightarrow{ }^{4} \mathrm{I}_{15 / 2}\right)$, (b) red $\left({ }^{4} \mathrm{~F}_{9 / 2} \rightarrow{ }^{4} \mathrm{I}_{15 / 2}\right)$, and $(\mathrm{c}) \mathrm{NIR}$ $\left({ }^{4} \mathrm{I}_{13 / 2} \rightarrow{ }^{4} \mathrm{I}_{15 / 2}\right) \mathrm{Er}^{3+}$ emissions, and (d) NIR $\left({ }^{4} \mathrm{~F}_{5 / 2} \rightarrow{ }^{4} \mathrm{~F}_{7 / 2}\right) \mathrm{Yb}^{3+}$ emission.

Table 2. It is observed that in general, the effective lifetimes for the 1:5SR sample are slower than the ones for the $1: 10$ SR sample. That fact suggests that the $1: 10$ SR sample might be subjected to more quenching processes than the $1: 5$ SR sample. The NIR effective lifetimes are most affected to the quenching processes by the increase of solvent for the $\mathrm{Yb}^{3+}$ as well $\mathrm{Er}^{3+}$ ions. This is because the $\mathrm{Yb}^{3+}\left({ }^{2} \mathrm{~F}_{5 / 2}\right)$, $\mathrm{Er}^{3+}\left({ }^{4} \mathrm{I}_{13 / 2}\right)$, and $\mathrm{Er}^{3+}\left({ }^{4} \mathrm{I}_{11 / 2}\right)$ energy levels are more sensible to $\mathrm{H}_{2} \mathrm{O}$ residuals. As a result, the visible emission will be lessened by an SR increase because the $\mathrm{Yb}^{3+}\left({ }^{2} \mathrm{~F}_{5 / 2}\right)$, $\mathrm{Er}^{3+}\left({ }^{4} \mathrm{I}_{13 / 2}\right)$ and $\mathrm{Er}^{3+}\left({ }^{4} \mathrm{I}_{11 / 2}\right)$ energy levels help to populate the VIS energy levels via upconversion process. The Visible emission quantum efficiency is reported in Table 2. This shows a slight decrease with an SR increase nevertheless the emission intensity is strongly dependent the SR change.

To establish the nature of the interaction between $\mathrm{Yb}^{3+}$ and $\mathrm{Er}^{3+}$ ions in $\mathrm{Y}_{2} \mathrm{O}_{3}$ we analyzed the experimental data using the Monte Carlo model (MC) described by (2). In such equations only the direct $\mathrm{Yb}^{3+}$ to $\mathrm{Er}^{3+}$ energy transfer processes $W\left(\mathrm{Yb}_{0}^{1} \rightarrow \mathrm{Er}_{2}^{0}\right), W\left(\mathrm{Yb}_{0}^{1} \rightarrow \mathrm{Er}_{3}^{1}\right)$, and $W\left(\mathrm{Yb}_{0}^{1} \rightarrow \mathrm{Er}_{4}^{2}\right)$ are considered and represent the cascading upconversion mechanism driven by nonradiative 
energy transfer processes. Note that the energy back transfer process $\left(\mathrm{Er}^{3+}\right.$ to $\left.\mathrm{Yb}^{3+}\right)$ is not considered since the measured lifetimes (see Table 2) for the ${ }^{2} \mathrm{~F}_{5 / 2}$ excited state of $\mathrm{Yb}^{3+}$ are short compared to the $0.8 \mathrm{~ms}$ values reported in bulk and ceramics [26]. Those short lifetimes suggest that the strong depopulation of the ${ }^{2} \mathrm{~F}_{5 / 2} \mathrm{Yb}^{3+}$ state is taking place and it might be due to strong direct $\mathrm{Yb}^{3+}$ and $\mathrm{Er}^{3+}$ energy transfer processes, which are stronger to any other processes that might induce repopulation of such state as is the case of the back transfer process. We considered dipole-dipole interaction to drive the energy transfers from $\mathrm{Yb}^{3+}$ to $\mathrm{Er}^{3+}$ ions, see (1). In order to use (1) we need to know the interionic distances between $\mathrm{Yb}^{3+}$ to $\mathrm{Er}^{3+}$ ions. We placed $N_{\mathrm{Yb}}$ ions of $\mathrm{Yb}^{3+}$ and $N_{\mathrm{Er}}$ ions of $\mathrm{Er}^{3+}$ with a uniform random distribution in $k$ numerically generated nanorods, and using the crystallographic data for the $\mathrm{Y}_{2} \mathrm{O}_{3}$ synthesized nanorods. Then, by solving (2) and (3), we computed fluorescence simulations for the green $\left(\left({ }^{2} \mathrm{H}_{11 / 2},{ }^{4} \mathrm{~S}_{3 / 2}\right) \rightarrow{ }^{4} \mathrm{I}_{15 / 2}\right)$, red $\left({ }^{4} \mathrm{~F}_{9 / 2} \rightarrow{ }^{4} \mathrm{I}_{15 / 2}\right)$, and NIR $\left({ }^{4} \mathrm{I}_{13 / 2} \rightarrow{ }^{4} \mathrm{I}_{15 / 2}\right) \mathrm{Er}^{3+}$ emissions as well as the NIR $\left({ }^{4} \mathrm{~F}_{5 / 2} \rightarrow{ }^{4} \mathrm{~F}_{7 / 2}\right) \mathrm{Yb}^{3+}$ emission, see Figure 6. The simulations shown in Figure 6 provide good representations of the experimental fluorescence decays of the ${ }^{4} \mathrm{I}_{13 / 2},{ }^{4} \mathrm{~F}_{9 / 2}$ and ${ }^{4} \mathrm{~S}_{3 / 2}$ states of the $\mathrm{Er}^{3+}$ and the ${ }^{4} \mathrm{~F}_{7 / 2}$ state of $\mathrm{Yb}^{3+}$ in the nanorod samples. The free parameters used to compute these fluorescence decay simulations are the dipole-dipole microinteraction parameters reported in Table 2. Notice that the $C\left(\mathrm{Yb}_{0}^{1} \rightarrow \mathrm{Er}_{2}^{0}\right)$ value for $1: 10 \mathrm{SR}$ is greater than that for $1: 5$. Such higher $C\left(\mathrm{Yb}_{0}^{1} \rightarrow \mathrm{Er}_{2}^{0}\right)$ value leads to the faster depopulation of the ${ }^{2} \mathrm{~F}_{5 / 2}\left(\mathrm{Yb}^{3+}\right)$ state in the $1: 10$ SR sample than for the $1: 5$ sample; see Table 2 and Figure 6(d). All other emission decays, both experimental and simulated, have almost the same decay trend. The main difference, among corresponding fluorescence decays is smaller intensity for the $1: 10$ SR sample. This agrees with the fact that the $C\left(\mathrm{Yb}_{0}^{1} \rightarrow \mathrm{Er}_{3}^{1}\right)$ and $C\left(\mathrm{Yb}_{0}^{1} \rightarrow \mathrm{Er}_{4}^{2}\right)$ parameters are almost the same for both samples; so the second and third $\mathrm{Yb}^{3+}$ to $\mathrm{Er}^{3+}$ energy transfers have the similar probabilities for both SRs. The biggest differences between experimental and model simulations correspond to the decay curves for the green emissions from the $\left({ }^{2} \mathrm{H}_{11 / 2},{ }^{4} \mathrm{~S}_{3 / 2}\right) \rightarrow{ }^{4} \mathrm{I}_{15 / 2} \mathrm{Er}^{3+}$ transition; see Figure 6(a). There, the simulated rise times are shorter than the experimental ones; this suggest the existence of additional depopulation channels of the ${ }^{2} \mathrm{H}_{11 / 2}$ ${ }^{4} \mathrm{~S}_{3 / 2}$ energy levels, such as $\mathrm{Er}^{3+}$ to $\mathrm{Yb}^{3+}$ energy back transfer processes, which have not been considered in our model. That also might be the reason why the experimental decays are under the simulated ones at intermediate times. In regard of the red emissions $\left({ }^{4} \mathrm{~F}_{9 / 2} \rightarrow{ }^{4} \mathrm{I}_{15 / 2} \mathrm{Er}^{3+}\right.$ transition) there is an excellent agreement between the experimental and simulated decay trends, in particular the rise times are very well predicted by the simulations. Notice the offset at $t=0$ between experimental and simulation curves for the NIR $\mathrm{Yb}^{3+}$ fluorescence decays (Figure 6(d)), such discrepancies for short times suggest that our model is not taking in to account additional channels of deexcitation, such as exchange interactions among dopant ion pairs or fast transfer processes to first neighbor radiation traps such as $\mathrm{OH}$ radicals at the nanorod surfaces. Nevertheless, with the most simple approach taken of considering only the main three $\mathrm{Yb}^{3+}$ to $\mathrm{Er}^{3+}$ direct energy transfer processes, $W\left(\mathrm{Yb}_{0}^{1} \rightarrow \mathrm{Er}_{2}^{0}\right), W\left(\mathrm{Yb}_{0}^{1} \rightarrow \mathrm{Er}_{3}^{1}\right)$, and $W\left(\mathrm{Yb}_{0}^{1} \rightarrow \mathrm{Er}_{4}^{2}\right)$, we have very good agreements between experimental results and its corresponding simulations. And we can conclude that the most important interaction is the first energy transfer process $W\left(\mathrm{Yb}_{0}^{1} \rightarrow \mathrm{Er}_{2}^{0}\right)$, that can be quantified by its microinteraction parameter $C\left(\mathrm{Yb}_{0}^{1} \rightarrow \mathrm{Er}_{2}^{0}\right)$. Also the microinteraction parameters depend on the size and morphology, which on time depends on the water to ethanol SR. Our simulations mesh with existing literature; this confirms the validity of our results. It should be noted, however, that our model is the only one that explains qualitatively the types of energy process as well as its magnitude, taking into account the dopant concentration, more than one exited state (energy levels), ions distribution, size, and shape of the nanocrystals.

\section{Conclusions}

In summary, we have measured the fluorescence lifetime of the ${ }^{4} \mathrm{I}_{13 / 2},{ }^{4} \mathrm{~F}_{9 / 2}$, and ${ }^{2} \mathrm{H}_{11 / 2},{ }^{4} \mathrm{~S}_{3 / 2}$ states of $\mathrm{Er}^{3+}$, and the ${ }^{4} \mathrm{~F}_{5 / 2}$ state of $\mathrm{Yb}^{3+}$ in $\mathrm{Y}_{2} \mathrm{O}_{3}: \mathrm{Yb}^{3+}, \mathrm{Er}^{3+}$ nanorods for two different SRs, $1: 5$ and $1: 10$. The effective lifetime, luminescent emissions, and nanorod sizes depend strongly on the SRs. The sample with 1:10 SR has lower effective lifetime and emission intensity than the sample with a $1: 5$ SR. The sample with $1: 5$ is bigger in size that $1: 10$ SR sample and both samples exhibit same cubic phase.

A novel method was proposed and implemented in order to explain the dynamics of the green and red upconversion emissions in $\mathrm{Yb}^{3+}-\mathrm{Er}^{3+}$-codoped $\mathrm{Y}_{2} \mathrm{O}_{3}$ Nanorods, taking into account the dopant concentration, more than one exited state (energy levels), ions distribution, size, and shape of the nanocrystals. A three-step nonradiative energy transfer model is proposed to explain the observed fluorescence decays characterized by dipole-dipole interactions. The corresponding microinteraction parameters are reported as well as quantum efficiency and effective lifetime for the visible emissions. Numerical simulations of fluorescence decays agree with experimental results. These results indicate that solvent concentration plays an important role on the upconversion luminescence processes, and therefore a change in the lifetime and quantum yield is observed.

\section{References}

[1] A. A. Kaminskii, Ed., Crystalline Lasers: Physical Processes and Operating Schemes, CRC, New York, NY, USA, 1996.

[2] D. K. Sardar, K. L. Nash, R. M. Yow, and J. B. Gruber, "Absorption intensities and emission cross section of intermanifold transition of $\mathrm{Er}^{3+}$ in $\mathrm{Er}^{3+}: \mathrm{Y}_{2} \mathrm{O}_{3}$ nanocrystals," Journal of Applied Physics, vol. 101, no. 11, Article ID 113115, 5 pages, 2007.

[3] S. A. Hilderbrand, F. Shao, C. Salthouse, U. Mahmood, and R. Weissleder, "Upconverting luminescent nanomaterials: application to in vivo bioimaging," Chemical Communications, no. 28, pp. 4188-4190, 2009.

[4] R. Martín-Rodríguez, R. Valiente, C. Pesquera et al., "Optical properties of nanocrystalline-coated $\mathrm{Y}_{2} \mathrm{O}_{3}: \mathrm{Er}^{3+}, \mathrm{Yb}^{3+}$ obtained by mechano-chemical and combustion synthesis," Journal of Luminescence, vol. 129, no. 9, pp. 1109-1114, 2009. 
[5] H. Dornauf and J. Heber, "Concentration-dependent fluorescence-quenching in $\mathrm{La}_{1-x} \operatorname{Pr}_{x} \mathrm{P}_{5} \mathrm{O}_{14}$," Journal of Luminescence, vol. 22, no. 1, pp. 1-16, 1980.

[6] F. Vetrone, J. C. Boyer, J. A. Capobianco, A. Speghini, and M. Bettinelli, "Effect of $\mathrm{Yb}^{3+}$ codoping on the upconversion emission in nanocrystalline $\mathrm{Y}_{2} \mathrm{O}_{3}$ :Er $\mathrm{Er}^{3+}$," Journal of Physical Chemistry B, vol. 107, no. 5, pp. 1107-1112, 2003.

[7] Y. Li, Y. Zhang, G. Hong, and Y. Yu, "Upconversion luminescence of $\mathrm{Y}_{2} \mathrm{O}_{3}: \mathrm{Er}^{3+}, \mathrm{Yb}^{3+}$ nanoparticles prepared by a homogeneous precipitation method," Journal of Rare Earths, vol. 26, no. 3, pp. 450-454, 2008.

[8] X. Li, Q. Li, J. Wang, and J. Li, "Hydrothermal synthesis of Er-doped yttria nanorods with enhanced red emission via upconversion," Journal of Luminescence, vol. 124, no. 2, pp. 351-356, 2007.

[9] T. Zako, H. Nagata, N. Terada et al., "Cyclic RGD peptidelabeled upconversion nanophosphors for tumor cell-targeted imaging," Biochemical and Biophysical Research Communications, vol. 381, no. 1, pp. 54-58, 2009.

[10] T. Forster, "Intermolecular energy migration and fluorescence," Annalen der Physik, vol. 2, pp. 55-75, 1948.

[11] D. L. Dexter, "A theory of sensitized luminescence in solids," Journal of Chemical Physics, vol. 21, no. 5, pp. 836-850, 1953.

[12] M. Inokuti and F. Hirayama, "Influence of energy transfer by the exchange mechanism on donor luminescence," Journal of Chemical Physics, vol. 43, no. 6, pp. 1978-1989, 1965.

[13] S. O. Vásquez, "Energy-transfer processes in quasibidimensional crystal arrays," Physical Review B, vol. 64, no. 12, Article ID 125103, 7 pages, 2001.

[14] V. A. Jerez, C. B. de Araújo, and Y. Messaddeq, "Dynamics of energy transfer and frequency upconversion in $\mathrm{Tm}^{3+}$ doped fluoroindate glass," Journal of Applied Physics, vol. 96, no. 5, pp. 2530-2534, 2004.

[15] D. Parisi, A. Toncelli, M. Tonelli, E. Cavalli, E. Bovero, and A. Belletti, "Optical spectroscopy of $\mathrm{BaY}_{2} \mathrm{~F}_{8}: \mathrm{Dy}^{3+}$," Journal of Physics: Condensed Matter, vol. 17, no. 17, pp. 2783-2790, 2005.

[16] G. M. Salley, R. Valiente, and H. U. Guedel, "Luminescence upconversion mechanisms in $\mathrm{Yb}^{3+}-\mathrm{Tb}^{3+}$ systems," Journal of Luminescence, vol. 94-95, pp. 305-309, 2001.

[17] A. Martínez, J. Morales, P. Salas, C. Angeles-Chávez, L. A. Díaz-Torres, and E. de la Rosa, "Synthesis and photoluminescence of $\mathrm{Y}_{2} \mathrm{O}_{3}: \mathrm{Yb}^{3+}-\mathrm{Er}^{3+}$ nanofibers," Microelectronics Journal, vol. 39, no. 3-4, pp. 551-555, 2008.

[18] O. Meza, L. A. Diaz-Torres, P. Salas, E. de la Rosa, C. AngelesChavez, and D. Solis, "Cooperative pair driven quenching of $\mathrm{Yb}^{3+}$ emission in nanocrystalline $\mathrm{ZrO}_{2}: \mathrm{Yb}^{3+}$," Journal of Nano Research, vol. 5, no. 1, pp. 121-134, 2009.

[19] J. T. Vega-Durán, L. A. Díaz-Torres, M. A. Meneses-Nava, J. L. Maldonado-Rivera, and O. Barbosa-García, "Optimal co-doping concentrations and dynamics of energy transfer processes for $\mathrm{Tm}^{3+}-\mathrm{Tb}^{3+}$ and $\mathrm{Tm}^{3+}-\mathrm{Eu}^{3+}$ in LiYF4 crystal hosts," Journal of Physics D, vol. 34, no. 21, pp. 3203-3208, 2001.

[20] L. Laversenne, Y. Guyot, C. Goutaudier, M. Th. Cohen-Adad, and G. Boulon, "Optimization of spectroscopic properties of $\mathrm{Yb}^{3+}$-doped refractory sesquioxides: cubic $\mathrm{Y}_{2} \mathrm{O}_{3}, \mathrm{Lu}_{2} \mathrm{O}_{3}$ and monoclinic $\mathrm{Gd}_{2} \mathrm{O}_{3}$," Optical Materials, vol. 16, no. 4, pp. 475483, 2004.

[21] M. J. Weber, "Radiative and multiphonon relaxation of rareearth ions in $\mathrm{Y}_{2} \mathrm{O}_{3}$," Physical Review, vol. 171, no. 2, pp. 283 291, 1968.
[22] G. Baldinozzi, J.-F. Bérar, and G. Calvarin, "Rietveld refinement of two-phase $\mathrm{Zr}$-doped $\mathrm{Y}_{2} \mathrm{O}_{3}$," Materials Science Forum, vol. 278, part 2, pp. 680-685, 1998.

[23] J. T. Vega-Durán, L. A. Díaz-Torres, O. Barbosa-García, M. A. Meneses-Nava, and J. F. Mosiño, "Exact solution to the general non-radiative energy transfer master equations in crystalline materials," Journal of Luminescence, vol. 91, no. 3, pp. 233-241, 2000.

[24] J. Kiusalaas, Numerical Methods in Engineering with Python, C.U. Press, 2005.

[25] J. R. Lakowicz, Principles of Fluorescence Spectroscopy, Springer, New York, NY, USA, 3rd edition, 2006.

[26] V. Peters, Growth and Spectroscopy of Ytterbium Doped Sesquioxides, Univerity of Hamburg, Hamburg, Germany, 2001. 

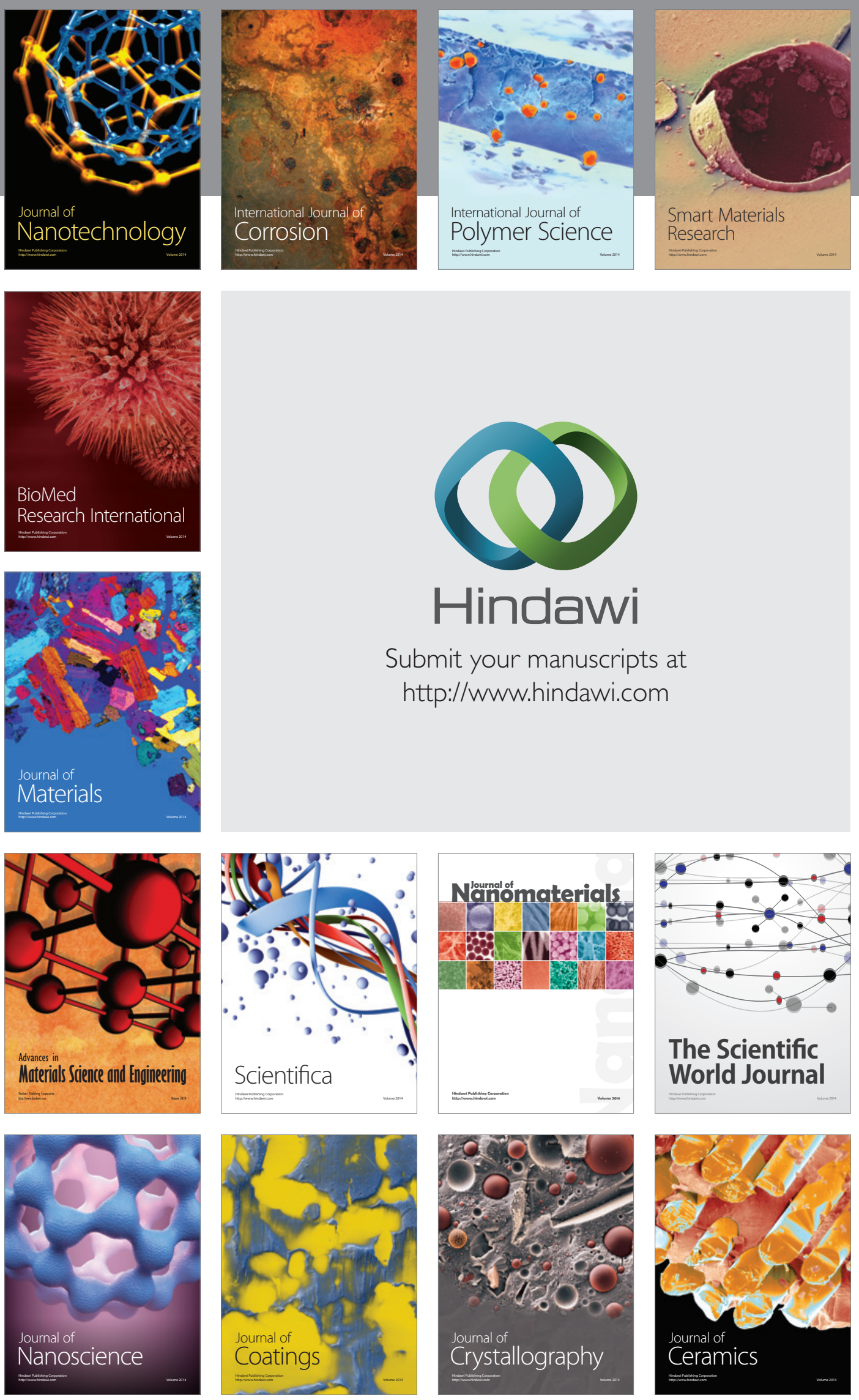

The Scientific World Journal

Submit your manuscripts at

http://www.hindawi.com

\section{World Journal}

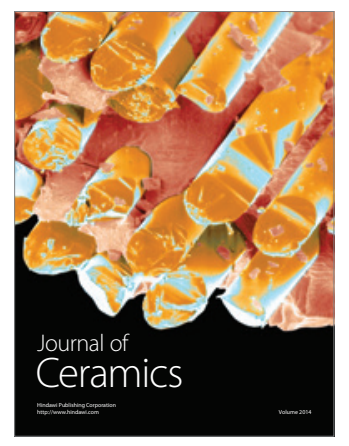

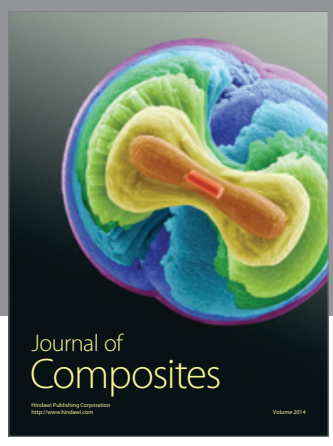
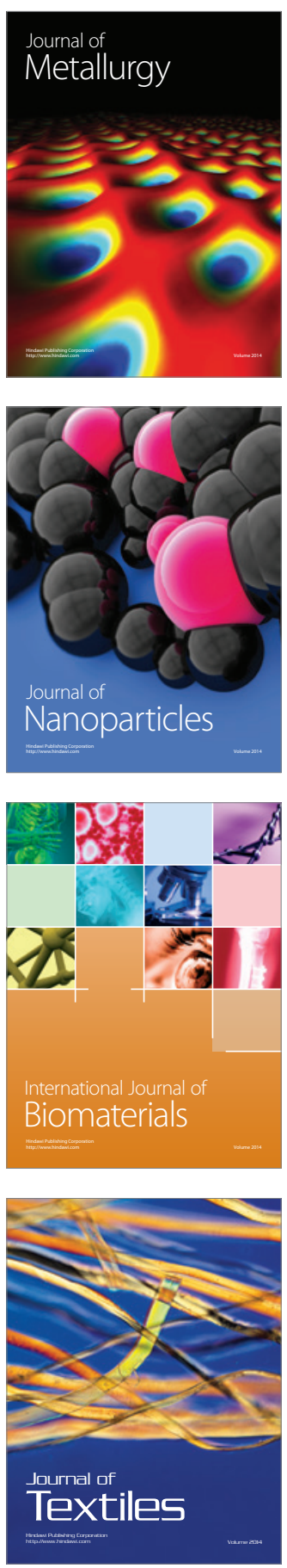